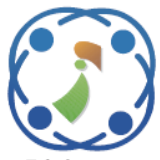

\title{
Energy Consumption Scheduling Using Adaptive Differential Evolution Algorithm in Demand Response Programs
}

\author{
Muthuselvi Gomathinayagam ${ }^{1 *}$ \\ Saravanan Balasubramanian ${ }^{1}$ \\ ${ }^{1}$ School of Electrical Engineering, Vellore Institute of Technology, Vellore, Tamilnadu, India \\ * Corresponding author's Email: gtecmuthuselvi@gmail.com
}

\begin{abstract}
Demand Side Management (DSM) provides a better solution in order to manage increased electricity demand in the power system network. The DSM program relieves the stress on the electrical network for maintaining power system reliability during peak hours. This work proposes a new scheduling approach based on an Adaptive Differential Evolution algorithm (ADEA) by considering a new recombination probability factor (CP) and real mutation factor $(\mathrm{F})$ for analysis. This proposed method is analyzed for industrial, commercial and residential network loads. The main aim of this demand control technique is to reduce the difference between the target curve and total load consumption curve. This paper provides a better solution compared to other algorithms like Evolutionary Approach (EA) and Symbiotic Organism Search (SOS) to reduce the peak load and electricity cost in industrial, commercial and residential distribution networks. The proposed method gives $8.2 \%$ peak load reduction compared to EA for residential area and $2.28 \%$ reduction in peak load when compared to SOS for commercial sector. Also it reduces the electricity cost at $17.25 \%, 20.76 \%$ and $21.15 \%$ for residential, commercial and industrial sectors when compared to without DSM. The participation factor of a consumer may be increased by price factor and the less violation in their scheduled demand. The described concept provides a relatively accurate fit to the target curve after load shifting. This concept will increase consumer participation in the DR Program.
\end{abstract}

Keywords: Smart grid, DSM, Demand response, ADEA.

\section{Introduction}

From its beginnings until recent times, the electric sector has remained unchanged in terms of the form and sources of generation, topology of its transmission and distribution network and the marketing of the service to a user with passive characteristics. Electric operators, usually vertically constituted state companies, generated the necessary energy and enough energy to supply consumers at all times. In this structure, the generation through traditional sources of energy (e.g., hydroelectric, oil, coal, etc.) was concentrated in a few large facilities and far from the consumption centers, where all the value chain of the sector was a monopoly of these companies.

The appearance and promotion of new technologies focused on residential users and small industries, such as electric transport or distributed energy resources (DER) grant them a more active role within the sector. Automation of certain charges allows a dynamic and intelligent adjustment of its power as in [1]. This change of role in residential users will allow them to eventually consume more energy but in a solidary and intelligent way with the system and at a lower cost. In order to incorporate these changes, the vertical structure of the electricity sector has been divided, encouraging restructuring in some of the stages of its value chain. The restructuring of the electricity markets has allowed the opening to new participants. In this model, the different generators compete to sell their energy production in the market of the distributors and the big consumers, using the rules of the competitive markets and under the supervision of an independent regulator of the controller. In the case of Uruguay, the Regulatory Framework Law and its regulations 


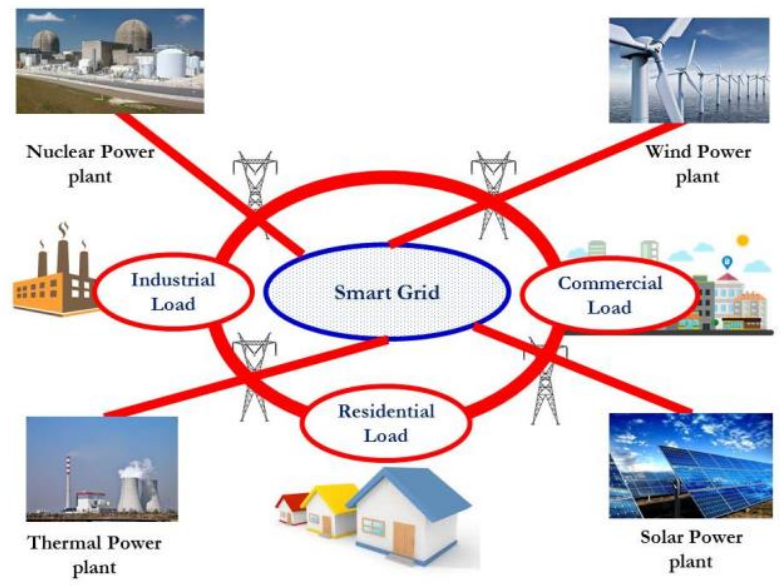

Figure. 1 Smart grid paradigm

establish the entry conditions for the agents interested in the generation of electric energy, its commercialization in the wholesale market [2] and the technical restrictions for its installation. The entry model in the wholesale market was through the creation of contracts with the only merchantenabled and some isolated cases forming contracts with large consumers, with marginal participation in the spot market.

These are some of the concepts that have motivated the appearance of intelligent electrical networks or better known as smart grids [SG] in the academic and industrial areas. The objective is to transform the current network into an intelligent, resilient and self-managing network, maintaining a service and quality of supply that meets the new needs. Fig. 1 shows the infrastructure of SG, for which the incorporation of new unattended functions and monitoring in real time is necessary. The use of the new communication technologies available facilitates the exchange of information between the different participants and promotes the development of control algorithms that maintain the stability of the network, adapting quickly and efficiently to changes.

The penetration of mini and micro-generation in the distribution network or the appearance of consumers in the system begins to position themselves and take relevance as one of the technological challenges to be faced. Energy transactions between geographically close customers (e.g. Clients from the same neighborhood), local networks or micro grids operating in isolation or switching between different sources of generation, virtual plants of generation acting on the distribution network, are some of the new emerging opportunities that start to position itself as the electrical network of the future. For retailers in the retail market, developing the ability to coordinate aggregate demand for their customers allows them to participate actively in wholesale markets. These possibilities allow offering different services to the electric system such as regulation, demand response or optimization of the physical resources of the network. This horizon of possibilities will point the way towards an optimized, decentralized and dynamic network, maximizing the efficiency of its markets and system resources, promoting new business models and mainly decreasing the cost of energy service.

In short, in this process of evolution of the electric sector, the operation of the network must adapt to the new sources of renewable generation, the penetration of DER technologies to the system and to the new more active and flexible role of the local users. In addition, service provider companies should be coupled to new decentralized business models, with the particular feature that the links of the value chain of the sector will be moving towards the borders of the same, even penetrating within the limits of the users.

The traditional grids are unable to meet the electricity demand because of day to day uncontrollable increasing loads. SG is a new paradigm of the traditional power grid and provides more advanced, reliable, efficient and dependable electrical services. The SG is an important platform for implementing new energy strategies, which is of great significant for adjusting energy structure, energy conservation, emission reduction, and coping with climate change.

SG has the features of automation, digitalization, and customer interaction in a smart and efficient way. It follows the duplex based communication protocol between the utility provider and the electricity consumer. Solving the gap between Supply and demand for electricity is the main issue in the smart grid. DSM program includes approaches of valley filling; peak clipping, peak load shifting, energy conservation, and energy growth to achieve the modification in the load shape of the consumers. Load shifting with smart pricing is a more efficient method in the DSM program to manage loads. Demand response (DR) in SG has the ability to reduce the peak demand [3] by modifying the load shape and thereby reducing the consumer's electricity bill. Modification of energy demand has been done through financial incentives and behavioral change. Home Energy Management Systems (HEMS) is used to achieve residential load management; without focusing on electricity pricing is discussed [4] but consumer satisfaction is not considered. Smart pricing tariffs are used in energy consumption scheduling. In $[5,6]$ Time of use 
(ToU) pricing is used to reduce and optimize the electricity demand and cost.

There are two load management approaches Direct Load Control and Smart Pricing in DR programs. By the first approach, the utility can remotely shift the usage of appliances from on-peak time to off-peak times [7]. Uncontrolled appliances may create a high peak to average ratio (PAR). With the second approach, incentives provided for active consumers participated in DR programs to manage their power usage. The main category of smart pricing are ToU, critical peak pricing, Real-time pricing and Day Ahead Pricing.

During period of peak energy demand (during hot summer days) the electric system may require more power. In CPP, the price for most of the time period in a day is fixed and high for a few period of time. In RTP, the price varies at different hours of the day. The varying prices may create uncomfortable for the users to respond. The tariff for each period is constant and predetermined in ToU pricing.

This paper is summarized as follows. Section 2 deals literature review of related work. Section 3 describes about the proposed Methodology. Section 4 details about the mathematical formulation related to proposed algorithms. Section 5 discuss about the simulation setup for the verification of the proposed algorithm. Section 6 details about the result and their analysis. Finally, section 7 concludes this work.

\section{Related works}

Most of the researches are based on algorithms, strategies, techniques and hybrid algorithms for the DSM in smart grid $[8,9]$. The behaviour of pricing signals such as RTP, TOU, and CPP are analyzed for optimized consumption scheduling of HEMS [10, 11], and [12]. Fuzzy based peak load reduction a smart grid environment is proposed in [13, 14]. Furthermore, hybrid grey wolf differential evolution (HGWDE) is implemented and is considered more number of appliances on a single home. The optimization problem is done for different smart pricing schemes.

In paper [15] cost efficiency based appliance scheduling is proposed. Based on different consumption patterns the cost efficiency can vary and is sensitive to behaviors of load shifting. In [16], a logarithmic pricing model was used to model the DSM problem. An effective incentive-based DR program is implemented $[17,18]$ based on customer reward scheme thereby the involvement of residential user participation is increased. In any DSM programs, customer's response/degree of participation is the main and strong impacts on the optimization process. Flexible load-shape shifting in DSM is achieved by cost characterization and customer acceptance and response. In [3], linear and restricted response of various customers is compared and the optimum incentive is determined. Demand response can increase short-term system capacity through price-based response schemes, avoiding or delaying peak capacity costs to meet peak loads. Although demand response technology can increase the price elasticity of user demand, the rising rate of renewable energy $[19,20]$ penetration increases the uncertainty of price-based demand response behaviour. At the same time, load participation demand should also be generated. Counter-effects, such as increasing the uncertainty of load forecasting and the actual negative volatility appropriately increasing the robustness of the unit combination can well suppress the effects of various uncertainties.

In a Collaborative scheduling operation management technology support platform, through the sharing of business data and the interaction of processes, realize unified management of plantrelated scheduling operations, which simplifies user access complexity and has good compatibility and scalability.

The scheduling problem was formulated by the game theory in [21-23]. A non-cooperative based continuous game is proposed to make the interactive model of the different consumer and a Stackelbergs game was used to represent their interaction with the service provider. In [24] proposed a game theory for scheduling the residential load. The pricing mechanism is considered on the basis of convex function for the analysis. Some incentive based approaches are proposed in $[25,27]$ by encouraging the consumers by reducing their usage during peak hours for efficient scheduling. A heuristic based energy consumption scheduling is proposed in [26]. This Evolutionary approach (EA) considered all types of end user in their analysis. The goal is to improvise the efficiency. This approach supports the shifting of peak load to some other off peak hour in a day. In [9] Symbiotic organisms search (SOS) algorithm is presented and also considered residential, industrial and commercial end users. It gives the better peak load reduction only for industrial area compared to logarithmic approach. It leads to the proposal of a new Meta heuristic approach so called an Adaptive differential evolution algorithm (ADEA) in this paper. 


\section{Proposed methodology}

The proposed algorithm can be summarized as follows. Our proposed algorithm is based on Adaptive differential evolution algorithm (ADEA). In differential evolution algorithm (DE) [28], feasibility oriented global search techniques are used. This process is used to solve the optimization problem in the direction of the feasible region. It is an Optimization algorithm for non-differentiable, non-continuous objectives. The major advantage of $\mathrm{DE}$ over $\mathrm{G} \mathrm{A}$ is that DE use mutation as the primary search process and selection process to guide the search in the direction of feasible regions which can be explained below the Eq. [1-4]. A more suitable F and $\mathrm{CP}$ parameter settings can be determined adaptively to match different stages of the search process. The setting of adaptive parameters $\mathrm{F}$ (Mutation factor) and $\mathrm{CP}$ (a recombination probability factor) can be calculated by Eq. (5) and (6).

A set of individual $I$ is called a population. Individual $I$ is a parameter which is used for optimization. Consider a population size of $N$ and $g$ is the generation.

The population matrix can be represented as

$$
\begin{gathered}
X_{n, i}^{g}=\left[X_{n, 1}^{g}, X_{n, 2}^{g}, X_{n, 3}^{g} \ldots \ldots \ldots . X_{n, I}^{g}\right] \\
i=1,2,3 \ldots . I \\
n=1,2,3 \ldots \ldots .
\end{gathered}
$$

The following steps are involved in EDEA.

\section{Mutation:}

Select three random vectors from each given vector. The differential value of two vectors is compared with the third vector and which is used to find mutated vector $V_{n}^{g+1}$.

This can be represented as

$$
\begin{array}{r}
V_{n}^{g+1}=X_{r 1, n}^{g}+F\left(X_{r 2, n}^{g}-X_{r 3, n}^{g}\right) \\
r 1 \neq r 2 \neq r 3 \neq n \\
n=1,2,3 \ldots \ldots . N
\end{array}
$$

Where, $F$ is the real mutation factor which controls the amplification/scaling value between the two vectors.

\section{Crossover:}

A trial vector $U_{n, i}^{g+1}$ is developed from population vector $X_{n, i}^{g}$ and is defined by Eq. (3):
$U_{n, i}^{g+1}=\left\{\begin{array}{cc}V_{n}^{g+1} & \text { if } \operatorname{rand}(i) \leq C P(\text { or }) i=I_{\text {rand }} \\ X_{n, i}^{g} & \text { otherwise }\end{array}\right.$

$I_{\text {rand }}$ is an integer random number between $[0,1]$. $C P$ is the recombination probability factor and it increases the diversity factor in a population.

\section{Selection:}

Comparison between the population vector $X_{n, i}^{g}$ and the trial vector $U_{n, i}^{g+1}$ gives the better fitness to the next generation using Eq. (4).

$X_{n, i}^{g}=\left\{\begin{array}{l}U_{n, i}^{g+1}, \quad \text { if } f\left(U_{n}^{g+1}<f\left(X_{n}^{g}\right)\right. \\ X_{n}^{g}, \text { otherwise }\end{array}\right.$

In ADEA [23], the value of and CP are relatively small at early and late stage, relatively fast increase in the middle, just to meet the global search and can be calculated by using Eq. (5).

$$
F=\left\{\begin{array}{c}
\alpha+(1-\alpha) \times \sin \left(\frac{\pi c}{\text { Iter }_{\max }}-\frac{\pi}{2}\right) \\
, \text { if }\left(c \leq \frac{\text { Iter }_{\max }}{2}\right) \\
\alpha-(1-\alpha) \times \cos \left(\frac{\pi}{2}-\frac{\pi c}{\text { Iter }_{\max }}\right) \\
, \text { otherwise }
\end{array}\right.
$$

$$
\begin{aligned}
& C P= \\
& \left\{\begin{array}{r}
\beta+(1-\beta) \times \sin \left(\frac{\pi c}{\text { Iter }_{\max }}-\frac{\pi}{2}\right) \\
, \text { if }\left(c \leq \frac{\text { Iter }}{2}\right) \\
\beta-(1-\beta) \times \cos \left(\frac{\pi}{2}-\frac{\pi c}{\text { Iter }_{\max }}\right) \\
, \text { otherwise }
\end{array}\right.
\end{aligned}
$$

Let the values of $\alpha$ and $\beta$ are constants. Assume $\alpha$ $=0.8$, and $\beta=0.75$ in the analysis. Iter max $_{\text {is }}$ is the maximum limit of iterations, and ' $c$ ' is the current iterations.

Parameter settings play the major role in the performance of the DE algorithm. But the problem characteristics significantly affect the choice of parameters. A more suitable $F$ and $C P$ parameter settings can be determined adaptively to match various stages of the search process.

\section{Mathematical formulation}

In this paper, the ADEA algorithm has been proposed to optimize the DSM load scheduling 
analysis. A large number of appliances and multiobjective functions can be handled by this proposed approach. In this mathematical model, the objective of DSM is to minimize consumer bill has been done through the reduction of the deviation between the target curve and total load consumption curve. Customer comfort is also considered for building an effective load shifting based DR program. The problem of load scheduling optimization that minimizes the total electricity cost of residential, industrial and commercial consumers.

Appliances classification: By considering energy and user comfort, the loads are classified as nonshiftable (Uncontrollable) and shiftable (controllable) type.

Non-shiftable appliances: They have a fixed operation period and power requirement. Examples: $\mathrm{TV}$, Electric stove, Refrigerator, and Lighting.

Shiftable appliances: For shiftable appliances, Scheduling is done to operate the appliances according to their power consumption and time. Example: PHEV, dishwasher, washing machine, and cloth dryer.

This paper is mainly focused on reducing peak load, cost and discomfort level. Our aim is to reduce the deviation between the load consumption curve and the objective load curve. The minimization of cost and load during peak can be calculated by the following Eqs. (7) and (8).

The minimization problem is expressed as,

(i) Minimize

$$
\text { Curve deviation }=\sum_{t=1}^{24}(P(t)-O(t))^{2}
$$

(ii) Minimize

$$
\text { Cost }=\sum_{t=1}^{24} P(t) \cdot C(t)
$$

Consider the objective load curve is inversely proportional to hourly based electricity price to this analysis.

The objective curve is formulated as in Eq. (9):

$$
O(t)=\left(\frac{\operatorname{Cavg}}{\operatorname{Cmax}}\right) \times \frac{1}{C(t)} \times \sum_{t=1}^{24} P(t)
$$

Where $P(t)=$ actual consumption of power at $\mathrm{t}$

$O(t)=$ objective curve at $t$ and

$C(t)=$ Cost at time $\mathrm{t}$

$P(t)$ can also be expressed as

$$
\begin{gathered}
P(t)=P_{\text {forecasted }(t)}+P_{\text {connect ( } t)}- \\
P_{\text {Disconnect }(t)}
\end{gathered}
$$

Amount of loads connected during shifting is represented as

$$
\begin{aligned}
& P_{\text {connect (i) }} \\
& =\sum_{\substack{i=1 \\
h-1}}^{t-1} \sum_{k=1}^{A} X_{k i t} \cdot P_{1 k} \\
& +\sum_{j=1}^{h-1} \sum_{i=1}^{t-1} \sum_{k=1}^{A} X_{k i(t-1)} \cdot P_{(1+j) k}
\end{aligned}
$$

Where, $A=$ Number of appliances types

$P 1 k, P(1+j) k=$ Consumptions of power for type $\mathrm{k}$ devices at first step $(1)$ and next step $(1+j)$.

$\mathrm{h}=$ total usage time of appliances (type $\mathrm{k}$ )

In the same manner the amount of loads disconnected during shifting can be expressed as,

$$
\begin{aligned}
& \sum_{q=t+1} \sum_{k=1}^{\text {Disconnect }(i)} X_{k t q} \cdot P_{1 k} \sum_{j=1}^{h-1} \sum_{q=t+1}^{t+m} \sum_{k=1}^{A} X_{k(t-1) q} \cdot P_{(1+j) k}
\end{aligned}
$$

Where

$m=$ Maximum permissible delay

$X_{k i t}=$ No.of devices (k type) shifted from time step i to $\mathrm{t}$

$X_{k t q}=$ No., of devices (k type) delayed from time step t to q.

\section{Constraints:}

The constraints used in this model are in Eqs. (13) and (14) which denote the number of shifted devices cannot be negative and shiftable appliances cannot be greater than available controllable appliances.

$$
\begin{aligned}
& X_{K i t}>0 \quad \forall i, j, k \\
& \sum_{t=1}^{24} X_{\text {Kit }} \leq \text { Controllable appliances }
\end{aligned}
$$

The fitness value is evaluated using Eq. (15) for finding the feasible solution.

$$
\text { Fitness }=\frac{1}{1+\sum_{t=1}^{24}(P(t)-O(t))^{2}}
$$

Higher priority loads may be shifted to the time period according to the consumer preference has been done by this algorithm. 


\subsection{ADEA algorithm}

In ADEA, the following steps are used to improve the performance of the algorithm for optimized scheduling.

\section{Algorithm 1 ADEA Algorithm. \\ 1: Initialize the size of population $(\mathrm{N})$, Max No., of iteration (Iter max $_{\text {ax }}$ ), mutation factor $F$ and Recombination probability factor (CP). \\ 2: Generate initial population using Eq. (1) \\ 3: Mutation. \\ Calculate mutated vector using Eq. (2) \\ Update Mutation factor (F) using (5) \\ 4: Crossover. \\ Calculate trial vector using Eq. (3); \\ Update Recombination probability factor (CP) using (6) \\ 5: Selection. \\ Select the fitness which is minimum and it is retained in the next generation using (4). \\ 6: End}

\section{Simulation environment}

The data of forecasted load demand and wholesale electricity prices of industrial, commercial and residential sectors for 24 hours are considered for simulation as given in Table 1-4. Less power consuming appliances that operate for short periods are considered in residential sectors. While in commercial, the ratings are slightly higher and in industrial sector ratings are higher and having longer duration of operation.

The Wholesale energy price plot is shown in Fig. 2 which shows cost in cents and time in hours.

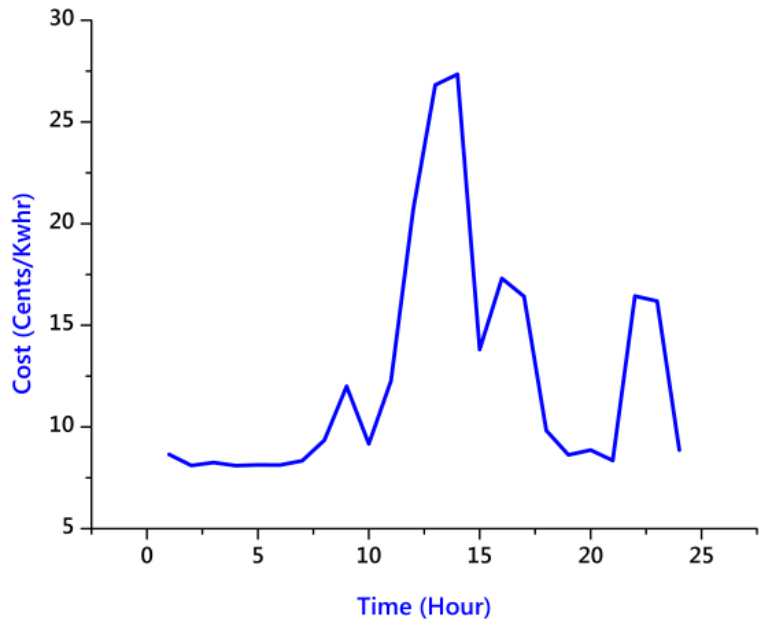

Figure. 2 Cost curve

\section{Simulation result}

The simulation result on peak load reduction for residential, commercial and industrial sectors as shown in Fig. 3-5. In all 3 sectors, the deviation between load after shifting curve and the objective curve is reduced and gives the better results compared to SoS and EA. Table 5 shows the comparison of peak load reduction using DSM with and without DSM. It is noted that the percentage reduction of peak load for residential (26.15\%), commercial (19.13\%) and industrial (15.14 \%) sectors by the proposed method is better than SOS and EA methods. Percentage Peak load Reduction comparison is shown in Table 6. The simulations have been carried out in MATLAB to validate the performance of the ADEA. The simulation results obtained for the residential sector are given in Fig. 3. The consumer cost of the residential sector reduces from $\$ 2302.90$ (without DSM strategy) to $\$ 1905.5$ (with DSM strategy), which is about $17.25 \%$ reduction in the operating cost. The simulation

Table 1. Input Data for 3 sectors

\begin{tabular}{ccccc}
\hline $\begin{array}{c}\text { Time } \\
\text { (Hours) }\end{array}$ & $\begin{array}{c}\text { Residential Load } \\
\text { (Kwh) }\end{array}$ & $\begin{array}{c}\text { Commercial Load } \\
(\text { Kwh })\end{array}$ & $\begin{array}{c}\text { Industrial Load } \\
(\text { Kwh })\end{array}$ & $\begin{array}{c}\text { Hourly Load } \\
\text { (Kwh) }\end{array}$ \\
\hline $\mathbf{0 - 1}$ & 475.7 & 404 & 974 & 1853.7 \\
$\mathbf{1 - 2}$ & 412.3 & 375.2 & 876.6 & 1664.1 \\
$\mathbf{2 - 3}$ & 364.7 & 375.2 & 827.9 & 1567.8 \\
$\mathbf{3 - 4}$ & 348.8 & 404 & 730.5 & 1483.3 \\
$\mathbf{4 - 5}$ & 269.6 & 432.9 & 730.5 & 1432.7 \\
$\mathbf{5 - 6}$ & 269.6 & 432.9 & 779.2 & 1481.4 \\
$\mathbf{6 - 7}$ & 412.3 & 432.9 & 1120.1 & 1965.3 \\
$\mathbf{7 - 8}$ & 539.1 & 663.8 & 1509.7 & 2712.6 \\
$\mathbf{8 - 9}$ & 729.4 & 923.5 & 2045.5 & 3698.4 \\
$\mathbf{9 - 1 0}$ & 713.5 & 1154.4 & 2435.1 & 4303 \\
$\mathbf{1 0 - 1 1}$ & 713.5 & 1443 & 2629.9 & 4786.4 \\
\hline
\end{tabular}




\begin{tabular}{lcccc}
\hline $\mathbf{1 1 - 1 2}$ & 808.7 & 1558.4 & 2727.3 & 5094.4 \\
$\mathbf{1 2 - 1 3}$ & 824.5 & 1673.9 & 2435.1 & 4933.5 \\
$\mathbf{1 3 - 1 4}$ & 761.1 & 1673.9 & 2678.6 & 5113.6 \\
$\mathbf{1 4 - 1 5}$ & 745.2 & 1673.9 & 2678.6 & 5097.7 \\
$\mathbf{1 5 - 1 6}$ & 681.8 & 1587.3 & 2629.9 & 4899 \\
$\mathbf{1 6 - 1 7}$ & 666 & 1558.4 & 2532.5 & 4756.9 \\
$\mathbf{1 7 - 1 8}$ & 951.4 & 1673.9 & 2094.2 & 4719.5 \\
$\mathbf{1 8 - 1 9}$ & 1220.9 & 1818.2 & 1704.5 & 4743.6 \\
$\mathbf{1 9 - 2 0}$ & 1331.9 & 1500.7 & 1509.7 & 4342.3 \\
$\mathbf{2 0 - 2 1}$ & 1363.6 & 1298.7 & 1363.6 & 4025.9 \\
$\mathbf{2 1 - 2 2}$ & 1252.6 & 1096.7 & 1314.9 & 3664.2 \\
$\mathbf{2 2 - 2 3}$ & 1046.5 & 923.5 & 1120.1 & 3090.1 \\
$\mathbf{2 3 - 2 4}$ & 761.1 & 577.2 & 1022.7 & 2361.0 \\
\hline
\end{tabular}

Table 2. Residential sector-shiftable appliances data

\begin{tabular}{lcccc}
\hline \multicolumn{1}{c}{ Appliance } & Number of devices & Hr 1 & Hr 2 & Hr 3 \\
\hline Dryer & 189 & 1.2 & - & - \\
Dishwasher & 288 & 0.7 & - & - \\
Washing machine & 268 & 05 & 0.4 & - \\
Oven & 279 & 1.3 & - & - \\
Iron & 340 & 1.0 & - \\
Vacuum cleaner & 158 & 0.4 & 0.2 & - \\
Fan & 288 & 0.2 & - \\
Kettle & 406 & 2.0 & \\
Toaster & 48 & 0.9 & \\
Rice cooker & 59 & 0.85 & 1.5 & \\
Hair dryer & 58 & 0.3 & \\
Blender & 66 & 1.1 & \\
Frying pan & 101 & 0.8 &
\end{tabular}

Table 3. Commercial sector-shiftable appliances data

\begin{tabular}{lcccc}
\hline \multicolumn{1}{r}{ Appliance } & Number of devices & Hr 1 & Hr 2 & Hr 3 \\
\hline Air Conditioner & 56 & 4 & 3.5 & 1.5 \\
Coffee Maker & 99 & 2 & 2 & - \\
Dryer & 117 & 3.5 & - & - \\
Fan & 93 & 3.5 & 3 & 3 \\
Kettle & 123 & 3 & 2.5 & - \\
Light & 87 & 2 & 1.75 & - \\
Oven & 77 & 5 & - & - \\
Water Dispenser & 156 & 2.5 & - & - \\
Total & $\mathbf{8 0 8}$ & & \\
\hline
\end{tabular}

Table 4. Industrial sector-shiftable appliances data

\begin{tabular}{lccccccc}
\hline Appliances & $\begin{array}{c}\text { No. } \\
\text { of devices }\end{array}$ & Hr 1 & Hr 2 & Hr 3 & Hr 4 & Hr 5 & Hr 6 \\
\hline Arc Furnace & 8 & 50 & 50 & 50 & 50 & 50 & 50 \\
Direct Current Motor & 6 & 150 & 150 & 150 & 150 & 150 & 150 \\
Fan/AC & 16 & 30 & 30 & 30 & 30 & 30 & - \\
Induction Motor & 5 & 100 & 100 & 100 & 100 & 100 & 100 \\
Welding Machine & 35 & 25 & 25 & 25 & 25 & 25 & - \\
Total & $\mathbf{1 0 9}$ & & & & & & \\
\hline
\end{tabular}


results obtained for the commercial sector are given in Fig. 4. The consumer cost of the commercial sector reduces from $\$ 3636.6$ (without DSM strategy) to $\$ 2881.3$ (with DSM strategy), which is about $20.76 \%$ reduction in the operating cost. The simulation results obtained for the industrial sector are given in Fig. 5. The consumer cost of the industrial sector reduces from \$5712.0(without DSM strategy) to $\$ 4503.9$ (with DSM strategy), which is about $21.15 \%$ reduction in the operating cost. Table 7 provides the comparative analysis of proposed DSM strategy along with existing methods like EA and SOS by considering industrial, commercial and residential sectors of the smart grid. The proposed ADEA method reduces the energy payment costs and peak load in considerable manners for all the three sectors when compared to the existing methods EA and SOS. It is interesting to note that the electricity cost of the residential $(17.25 \%)$ industrial $(21.15 \%)$ and commercial sectors $(20.76 \%)$ are reduced when compared to the existing state of art works.

This paper proposed the demand control technique based on optimized scheduling approaches using ADEA. For all the three sectors, the deviation between shifting load curve and the expected objective load curve is reduced more while compared to the EA and SOS. Based on the obtained results of the proposed ADEA the minimization of energy payment costs and peak load reduction for all the three sectors are attained.

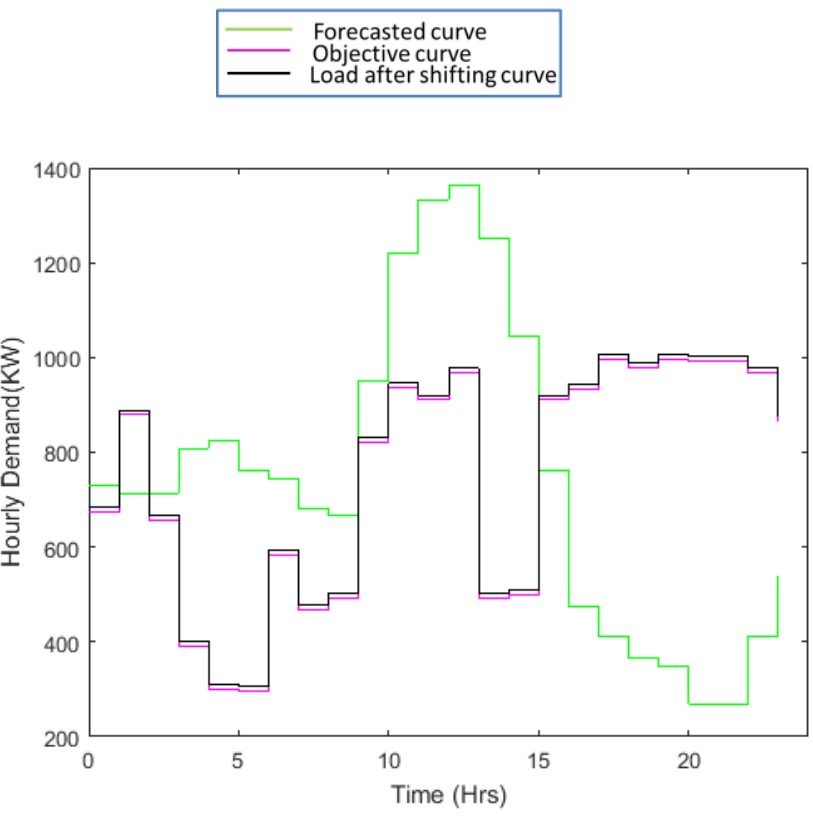

Figure. 3 DSM curve for Residential sector

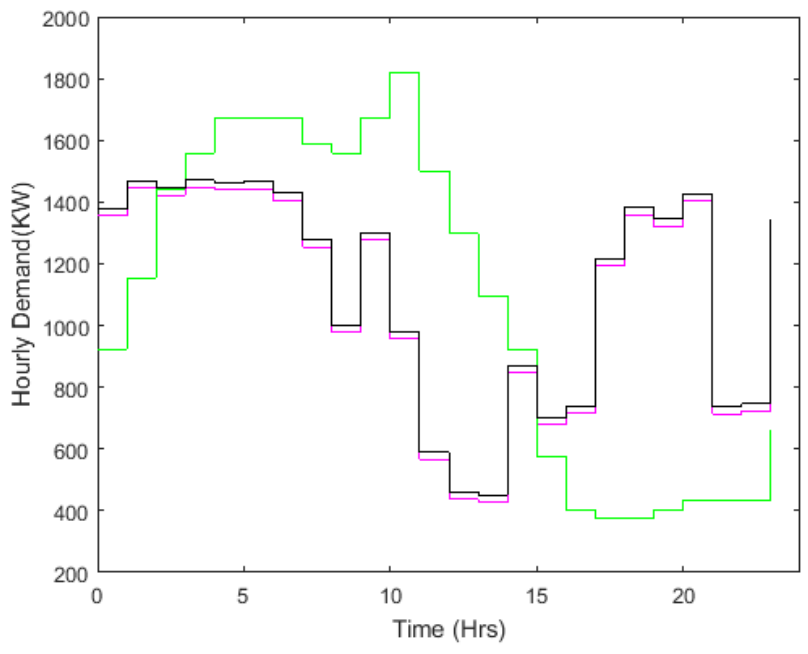

Figure. 4 DSM curve for commercial sector

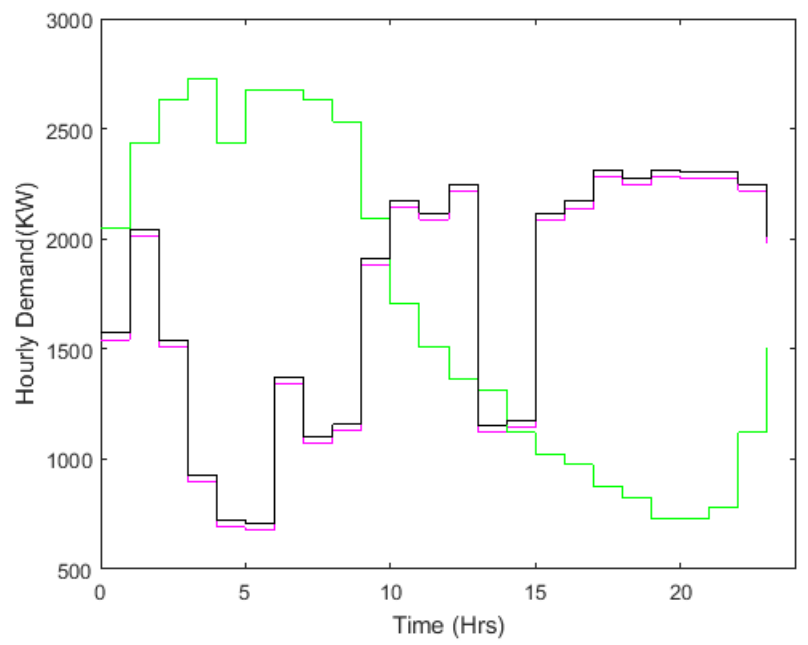

Figure. 5 DSM curve for industrial sector

\section{Conclusion}

The proposed work in this paper, mainly discuss the minimization of peak load and cost in the DSM by considering various sectors like industrial, commercial and residential sectors in the smart grid. For an effective DSM strategy to be implemented, the involvement of both utility and customers is important. The participation factor of the consumer may be increased by price factor and the less violation in their scheduled demand. Utility satisfaction level will be decided by less violation in their objective demand. So there is a trade-off between utility and consumer. In this proposed Adaptive Differential Evolution algorithm (ADEA) method, the simulation analysis proves that load after shifting curve which follows the objective curve and the minimization of energy payment costs and peak load reduction for all the three sectors are attained. Thus the discomfort/inconvenience level of customers can be reduced. The proposed method 
Table 5. Peak load comparison with and without DSM

\begin{tabular}{|c|c|c|c|c|c|c|c|}
\hline \multirow[t]{3}{*}{ Area } & \multicolumn{4}{|c|}{ Peak Load (KW) } & \multicolumn{3}{|c|}{ Peak Reduction (KW) } \\
\hline & \multirow{2}{*}{ No DSM } & \multicolumn{3}{|c|}{ DSM } & \multirow[b]{2}{*}{$\begin{array}{c}\text { EA } \\
{[26]}\end{array}$} & \multirow[b]{2}{*}{$\begin{array}{c}\text { SOS } \\
{[9]}\end{array}$} & \multirow[b]{2}{*}{ Proposed } \\
\hline & & $\begin{array}{c}\text { EA } \\
{[26]}\end{array}$ & $\begin{array}{c}\text { SOS } \\
{[9]}\end{array}$ & Proposed & & & \\
\hline Residential & 1363.6 & 1114.4 & 1033.3 & 1007.0 & 249.2 & 330.3 & 356.6 \\
\hline Commercial & 1818.2 & 1485.9 & 1511.8 & 1470.2 & 333 & 306.4 & 348 \\
\hline Industrial & 2727.3 & 2343.6 & 2355.2 & 2314.4 & 383.7 & 372.1 & 412.9 \\
\hline
\end{tabular}

Table 6. Peak load Reduction comparison

\begin{tabular}{llll}
\hline Type of Area & \multicolumn{2}{l}{ Percentage Reduction of peak load (\%) } \\
\cline { 2 - 4 } & EA [26] & SOS [9] & Proposed \\
\hline Residential & 18.3 & 24.22 & $\mathbf{2 6 . 1 5}$ \\
Commercial & 18.3 & 16.85 & $\mathbf{1 9 . 1 3}$ \\
Industrial & 14.2 & 13.64 & $\mathbf{1 5 . 1 4}$ \\
\hline
\end{tabular}

Table 7. Cost comparison with and without DSM

\begin{tabular}{cccccccc}
\hline \multirow{2}{*}{ Type of Area } & $\begin{array}{c}\text { Cost } \\
\text { without } \\
\text { DSM }\end{array}$ & \multicolumn{3}{c}{ Cost with DSM (dollar) } & \multicolumn{3}{c}{ Percentage Reduction (\%) } \\
\cline { 3 - 8 } & EA [26] & SOS [9] & Proposed & EA [26] & SOS [9] & Proposed \\
\hline Residential & 2302.9 & 2188.3 & 1914.7 & $\mathbf{1 9 0 5 . 5}$ & 5.0 & 16.86 & $\mathbf{1 7 . 2 5}$ \\
Commercial & 3636.6 & 3424.3 & 2938.9 & $\mathbf{2 8 8 1 . 3}$ & 5.8 & 19.17 & $\mathbf{2 0 . 7 6}$ \\
Industrial & 5712.0 & 5141.6 & 4578.6 & $\mathbf{4 5 3 0 . 9}$ & 10.0 & 19.84 & $\mathbf{2 1 . 1 5}$ \\
\hline
\end{tabular}

gives better result of $8.2 \%$ peak load reduction compared to EA for residential area and $2.28 \%$ reduction in peak load when compared to SOS for commercial sector.

\section{References}

[1] V.C. Gungor, "A Survey on Smart Grid Potential Applications and Communication Requirements", IEEE Transactions on Industrial Informatics, Vol.9, No.1, pp. 28-42, 2013.

[2] M.H. Albadi and E.F. El-Saadany, "A summary of demand response in electricity markets", Electric Power Systems Research, Vol.78, No. 11, pp. 1989-1996, 2008.
[3] M. A. F. Ghazvini, P. Faria, S. Ramos, H. Morais, and Z. Vale, "Incentive based demand response programs designed by asset-light retail electricity providers for the day-ahead market", Energy, Vol. 82, pp. 786-799, 2015.

[4] J. Abushnaf, A. Rassau, and W. Gornisiewicz, "Impact on electricity use of introducing timeof-use pricing to a multi-user home energy management system", International Transactions on Electrical Energy Systems, Vol. 26, No. 5, pp. 993-1005, 2015.

[5] A. Khalid, N. Javaid, M. Guizani, M. Alhussein, K. Aurangzeb, and M. Ilahi, "Towards Dynamic Coordination Among Home Appliances Using Multi-Objective Energy Optimization for Demand Side 
Management in Smart Buildings", IEEE Access, Special Section on Energy Management in Buildings, Vol. 6, No. 4, pp. 19509-19529, 2018.

[6] M. Naz, Z.Iqbal, N. Javaid, Z.A. Khan, W. Abdul, A. Almogren and A. Alamri, "Efficient Power Scheduling in Smart Homes Using Hybrid GreyWolf Differential Evolution Optimization Technique with Real Time and Critical Peak Pricing Schemes", Energies, Vol. 11, No. 2, pp. 384-392, 2018.

[7] L. Gelazanskas and K. A. Gamage, "Demand side management in smart grid: A review and proposals for future direction", Sustainable Cities and Society, Vol. 11, No. 4, pp. 15-64, 2014.

[8] M. Shinwari, A. Youssef, and W. Hamouda, "A Water-Filling Based Scheduling Algorithm for the Smart Grid", IEEE Transactions on Smart Grid, Vol. 3, No. 2, pp. 710-719, 2012.

[9] Niharika and V. Mukherjee, "Day-ahead demand side management using symbiotic organisms search algorithm", IET Generation, Transmission and Distribution, Vol. 12, No. 14, pp. 3487-3494, 2018.

[10] G. Pau, M. Collotta, A. Ruano, and J. Qin, "Smart home energy management", Energies, Vol.10, No.12, p.382-387, 2017.

[11] S. Shao, T. Zhang, M. Pipattanasomporn, and S. Rahman, "Impact of TOU rates on distribution load shapes in a smart grid with PHEV penetration", In: Proc. of IEEE PES Transmission Distribution Conf. Expo., pp. 16, 2010.

[12] G. Koutitas and L. Tassiulas, "A delay based optimization scheme for peak load reduction in the smart grid", In: Proc. of the 3rd International Conf. Future Energy Syst.: Where Energy, Computer and Communication Meet, pp. 1-4, 2012.

[13] B. Qela and H.T. Mouftah, "Peak Load Curtailment in a Smart Grid Via Fuzzy System Approach", IEEE Transaction on Smart Grid, Vol. 5, No. 2, 761-768, 2014.

[14] R. Gamperle, S. D. Muller, and P. Koumoutsakos, "A parameter study for diferential evolution", Advances in Intelligent Systems, Fuzzy Systems, Evolutionary Computation, Vol. 10, No. 3, pp.293-298, 2002.

[15] J. Ma, H. Chen, L. Song, and Y. Li, "Residential Load Scheduling in Smart Grid: A Cost Efficiency Perspective", IEEE
Transaction on Smart Grid, Vol. 7, No. 2, pp. 771-784, 2016.

[16] B. Saravanan, "DSM in an area consisting of residential,commercial and industrial load in smart grid", Front. Energy, Vol. 9, No. 2, pp. 211-216, 2015.

[17] D.H. Vu , K.M. Muttaqi, A.P. Agalgaonkar, and A. Bouzerdoum, "Customer reward-based demand response program to improve demand elasticity and minimise financial risk during price spikes", IET Generation, Transmission and Distribution, Vol. 12, No. 15, pp. 37643771, 2018.

[18] L. Song, Y. Xiao, and M. van der Schaar, "Demand Side Management in Smart Grids Using a Repeated Game Framework", IEEE Journal on Selected Areas in Communications, Vol. 32, No. 7, pp. 1412-1424, 2014.

[19] H. Wu, A. Pratt, and S. Chakraborty, "Stochastic optimal scheduling of residential appliances with renewable energy sources", In: Proc. of IEEE Power \& Energy Society General Meeting, pp. 1-5, 2015.

[20] A. Safdarian, M. Fotuhi-Firuzabad, and M. Lehtonen, "Optimal Residential Load Management in Smart Grids:Decentralized Framework", IEEE Transaction on Smart Grid, Vol.7, No. 4, pp. 1836-1845, 2016.

[21] B. Gao, W. Zhang, Y. Tang, M. Hu, M. Zhu and H. Zhan, "Game-Theoretic Energy Management for Residential Users with Dischargeable Plug-in Electric Vehicles", Energies, Vol. 7, No. 3, pp.7499-7518, 2014.

[22] Z. Fadlullah, D. Quan, N. Kato, and I. Stojmenovic, "GTES: An optimized gametheoretic demand side management scheme for smart grid", IEEE Systems Journal, Vol. 8, No. 2, pp. 588-597, 2014.

[23] H.M. Soliman and A. Leon-Garcia, "GameTheoretic Demand-Side Management With Storage Devices for the Future Smart Grid”, IEEE Transaction on Smart Grid, Vol. 5, No. 3, pp.1475-1485, 2014.

[24] A.H. Mohsenian-Rad, V.W.S. Wong, J. Jatskevich, R. Schober, and A. Leon-Garcia, "Autonomous demand-side management based on game-theoretic energy consumption scheduling for the future smart grid", IEEE Transaction on Smart Grid, Vol. 1, No. 3, pp. 320-331, 2010.

[25] Q. Hu, F. Li, X. Fang, L. Bai, "A framework of residential demand aggregation with financial incentives", IEEE Transaction 
on Smart Grid, Vol. 9, No. 1, pp. 497-505, 2018.

[26] T. Logenthiran, D. Srinivasan, and T.Z. Shun, "Demand Side Management in Smart Grid Using Heuristic Optimization", IEEE Transaction on Smart Grid, Vol. 3, No. 3, pp.1242-1252, 2012.

[27] M. Clark and L. Lampe, "Electrical Grid Peak Reduction With Efficient and Flexible Automated Demand Response Scheduling", In: Proc. of IEEE $28^{\text {th }}$ Canadian Conf. on Electrical and Computer Engineering, pp. 818-823, 2015.

[28] X. Yuana, Y. Zhang, L. Wang, Y. Yuan, “An enhanced differential evolution algorithm for daily optimal hydro generation scheduling", Computers and Mathematics with Applications, Vol. 6, No. 4, pp. 2458-2468, 2008. 